\title{
ANTIBACTERIAL ACTIVITY OF OCIMUM SPECIES AND THEIR PHYTOCHEMICAL AND ANTIOXIDANT POTENTIAL
}

\author{
PRASAD M.P.*, JAYALAKSHMI K. AND RINDHE G.G. \\ Sangenomics Research Labs, Bangalore-560 071, Karnataka, India. \\ *Corresponding Author: Email- prasad_m_p@hotmail.com
}

Received: July 05, 2012; Accepted: September 11, 2012

\begin{abstract}
Since ages, many plants have been used for preservative and medicinal purposes due to the presence of secondary metabolites referred as Phytochemicals. Phytochemicals are biologically active plant compounds having disease hampering capabilities and preservative action. The genus Ocimum contains more than 200 species of herbs and shrubs which have been shown to have medicinal properties and also are used as a culinary herb, preservative and flavoring agents. In this study methanol extracts from the leaves of Ocimum species ( 0 . sanctum purple, 0 . sanctum green, 0 . gratissimum, 0 . basilicum and Camphor basil) were investigated for their phytochemical constituent and antioxidant activity. Also, six extracts (Ethanol, Methanol, Propanol, Chloroform, Petroleum Ether and Isoamyl alcohol) were assayed to test their ability to inhibit the clinically isolated Enterobacteria (S. pneumoniae, Proteus sp., E. faecalis, $S$. typhi, S. aureus and B. subtilis). The Ocimum sp. were screened for the presence of phenolic content, glycosides, anthraquinones, terpenoids, proteins, flavinoids, tannins, lignin and Saponins. The test results were positive for all Phytochemicals in methanolic extracts of Ocimum $s p$. The antioxidant activity was measured by reducing power assay, 1-1-diphenyl-2-picrylhydrazyl (DPPH) assay and Thiobarbituric acid (TBA) which showed positive. In the antimicrobial assay studies 0 . gratissimum and 0 . basilicum showed maximum antibacterial activity compared to other species with maximum activity in isoamyl alcohol extract. The Present investigation suggests that the phytochemical content and its antioxidant properties can be further studied for its application in health and in food industries. Furthermore, these species can be used as a source of novel drugs for the treatment of infectious diseases caused by pathogenic microorganisms.
\end{abstract}

Keywords- Ocimum, Phytochemicals, Antioxidant Activity, Antibacterial Activity

Abbreviations- Osp- O. sanctum purple, Osg- 0 . sanctum green, Og- O. gratissimum, Ob- O. basilicum, Cb- Camphor basil

Citation: Prasad M.P., et al. (2012) Antibacterial Activity of Ocimum Species and Their Phytochemical and Antioxidant Potential. International Journal of Microbiology Research, ISSN: 0975-5276 \& E-ISSN: 0975-9174, Volume 4, Issue 8, pp.-302-307.

Copyright: Copyright@2012 Prasad M.P., et al. This is an open-access article distributed under the terms of the Creative Commons Attribution License, which permits unrestricted use, distribution and reproduction in any medium, provided the original author and source are credited.

\section{Introduction}

Plants are the richest resource of drugs of traditional systems of medicine, modern medicines, nutraceuticals, food supplements, folk medicines, pharmaceutical intermediates and chemical entities for synthetic drugs [1]. Traditional medical system has great value and also many medicinal plants have been identified from indigenous pharmacopoeias, because of which plants are still making imperative contribution to healthcare regardless of modern medicines which has many advances [2]. The medicinal values of plants lie in their Phytochemicals, which produce definite physiological actions on the human body. Phytochemicals are compounds present in plants that are used as food and medicine to protect against illness and to maintain human health [3]. Phytochemicals have antioxidant or hormone-like effect which helps in fighting against many diseases including cancer, heart disease, diabetes, high blood pressure and preventing the formation of carcinogens on their target tissues [4]. Medicinal plants have been found to be helpful in curing many diseases and have always promoted the search for different extracts from plants which could act as a potential source of new antimicrobial agent [5,6]. Spice plants have been used traditionally as coloring agents, flavoring agents, preservatives, food additives and as well as antiparasitic, antihelmintic, analgesic, expectorant, sedative, antiseptic and anti-diabetic substances in many parts of the world [7]. In addition, they possess biological activities such as that of antioxidants [8] and hypocholesterolemics [9]. Thousands of medicinal species found in different parts of the India are being used from the ancient time and are of great medicinal and economical value [10].

In recent years, it has been seen that because of indiscriminate use of commercial antimicrobial drugs, rate of acquiring multiple resistances in human pathogenic microorganisms has increased [11]. This fact has led the scientists to search for novel antimicrobial substances and screen medicinal plants regularly for new antibacterial agents. The genus Ocimum comes under Lamiaceae 
family and is found in many part of the world like tropical and subtropical regions of Asia, Africa and Central and South America. It is a source of essential oils and aroma compounds, a culinary herb and an attractive, fragrant ornamental plant. Tulasi is considered as a sacred plant and its various medicinal properties have been mentioned in ancient medicinal text, Ayurveda. Different parts of this plant are used for treatment of various ailments. Ocimum is believed to decrease lipid peroxidation and increase the activity of superoxide dismutase [12]. The constituents of Ocimum species have antibacterial, antifungal, antioxidant and radio protective activity $[13,14]$. Studies show that many Ocimum species are useful for the treatment of disorders in central nervous system (CNS) and also as antidepressant $[2,15]$.

Oxygen derived free radicals and reactive oxygen species (ROS) plays role in many diseases and in food deterioration and spoilage [4], by inhibiting the initiation or propagation of oxidative chain reactions, Antioxidants can delay or inhibit the oxidation of lipids or other molecules [16]. Synthetic antioxidants used in foods are very unstable and thought to be carcinogenic, because of which interest in finding out new natural and non toxic antioxidants is increasing [17]. Though much antibacterial and phytochemical studies has been conducted on Ocimum species, keeping in view the pharmacology, the present work has been designed to screen antimicrobial agents by using various solvent extracts and their action on various pathogens and also to evaluate the antioxidant potential of the extracts to explore the basis for its traditional use.

\section{Materials and Methods}

\section{Plant Material}

The plant material of Ocimum species were obtained from the local area in and around Ernakulam District, Kerala and University of agriculture, Bangalore India. The plants were indentified based on their description given in the literature. The plant leaves were air dried under shade and powdered. $1 \mathrm{gm}$ powder sample was dissolved in $100 \mathrm{ml}$ distilled water and used for qualitative phytochemical analysis.

\section{Preliminary Phytochemical Analysis}

Phytochemical screening of plant extracts was done by the standard procedure [18]. All the prepared plant extracts were subjected to preliminary phytochemical screening for the presence of phenolic content, glycosides, anthraquinones, terpenoids, proteins, flavinoids, tannins, lignin and Saponins.

\section{Quantitative Analysis of Phytochemicals}

\section{Alkaloid Determination}

$0.15 \mathrm{gm}$ of the sample was taken in test tube and $5 \mathrm{ml}$ of $20 \%$ acetic acid in ethanol was added and covered to stand for $4 \mathrm{hrs}$. This was centrifuged and the supernatant was concentrated using a waterbath to one-quarter of the original volume. Concentrated ammonium hydroxide was added drop wise to the extract until the precipitation was complete. The whole solution was allowed to settle and the precipitate was collected by filtration and weighed $[18,19]$.

\section{Tannin Determination}

$0.1 \mathrm{gm}$ of the sample was weighed to which $10 \mathrm{ml}$ of distilled water was added and shaken for $1 \mathrm{hr}$. in a mechanical shaker. This was centrifuged and $1 \mathrm{ml}$ of the filtrate was pipette out into a tube and mixed with $200 \mu$ l of $0.1 \mathrm{M} \mathrm{FeCl} 3$ in $0.1 \mathrm{~N} \mathrm{HCl}$ and $0.008 \mathrm{M}$ potassium ferrocyanide. The absorbance was measured in a colorimeter at $670 \mathrm{~nm}$ wavelength, within $10 \mathrm{~min}$. A blank sample was prepared with the reagent and distilled water and the absorbance taken at same wavelength [20].

\section{Determination of Total Phenols}

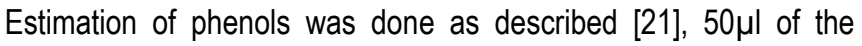
aqueous extract of the sample was mixed with $1.5 \mathrm{~mL}$ of FolinCiocalteau's reagent (diluted 1:2) and $1.2 \mathrm{~mL}$ of $20 \% \mathrm{Na}_{2} \mathrm{CO}_{3}$. The contents were mixed and incubated in dark at room temperature for 30 mins. Phenol reacts with the phosphomolybdic acid present in the FC-reagent in alkaline medium to form a blue colored complex which can be measured at $765 \mathrm{~nm}$ using a spectrophotometer.

\section{Flavonoid Determination}

$20 \mu \mathrm{g}$ of the plant samples were extracted repeatedly with $2 \mathrm{ml}$ of $80 \%$ aqueous methanol at room temperature. The whole solution was centrifuged. The supernatant was later transferred into an eppendorf tube and evaporated to dryness in a hot air oven and weighed [22].

\section{Antioxidant Assay}

\section{Extract Preparation for Antioxidant Activity}

For extraction, $5 \mathrm{gm}$ powder of Ocimum was mixed with $50 \mathrm{ml}$ of methanol. Extraction continued until the extraction solvents became colorless. The obtained extracts were filtered over Whatmann No.1 paper and the filtrate was collected, then methanol was removed by evaporation.

\section{DPPH (1, 1-diphenyl-2-picrylhydrazyl) free radical scavenging assay}

Scavenging activity on DPPH was assessed according to the method reported by [23] with a slight modification. Briefly, 500 $\mu$ l of extracts $(0.2$ to $1 \mathrm{mg} / \mathrm{ml})$ were mixed with $3 \mathrm{ml}$ of methanolic solution of $0.1 \mathrm{mM} \mathrm{DPPH}$. The mixture was shaken well and incubated at room temperature for $30 \mathrm{~min}$ and absorbance was measured at $517 \mathrm{~nm}$ in a spectrophotometer. Experiment was performed in triplicate and average was taken for determination of percentage inhibition.

\section{Reducing Power Assay}

The reducing power of extracts was determined by following method $0.5 \mathrm{ml}$ of extracts $(0.2$ to $1 \mathrm{mg} / \mathrm{ml})$ was mixed with $0.5 \mathrm{ml}$ of $0.2 \mathrm{M}$ phosphate buffer ( $\mathrm{pH} 6.6)$ and $0.5 \mathrm{ml}$ potassium ferrocyanide (1\%). After incubating the mixture at $50^{\circ} \mathrm{C}$ for $20 \mathrm{~min}$., $0.5 \mathrm{ml}$ of $10 \%$ trichloroacetic acid was added and then mixture was centrifuged at $3000 \mathrm{rpm}$ for $10 \mathrm{~min}$. $1 \mathrm{ml}$ of supernatant was mixed with $1 \mathrm{ml}$ of distilled water and $0.2 \mathrm{ml} \mathrm{FeCl} 3(0.1 \%)$ and the absorbance was measured at 700 .

\section{Thiobarbituric Acid (TBA) Method}

The method of [24] was referred; $1 \mathrm{ml}$ of $20 \%$ trichloroacetic acid and $1 \mathrm{ml}$ of $0.67 \%$ 2-thiobarbituric acid was added to $0.5 \mathrm{ml}$ of sample solution prepared in ethanol. The mixture was placed in a boiling water bath. After cooling, absorbance of supernatant was measured at $552 \mathrm{~nm}$. 


\section{Antibacterial Activity}

\section{Collection of Microorganisms for Antibacterial Activity}

The pathogenic microorganism were isolated from clinical samples collected from diagnostic testing labs and indentified on the basis of morphological, biochemical and physiological characteristics according to Bergey's manual of determinative bacteriology. The isolated microorganisms were found to be $K$. pneumoniaee, Proteus sp., E. faecalis, S. typhi, S. aureus and B. subtilis.

\section{Solvent Extraction}

Plant leaves were dried under shade and dried leaves were crushed using mortar and pestle. Then $5 \mathrm{gm}$ of crushed plant material was kept on rotary shaker along with $50 \mathrm{ml}$ of different solvents for 2 days. The extract was concentrated by solvent evaporation and used for antimicrobial activity.

\section{Determination of Antimicrobial Activity}

The antimicrobial activity was determined by the agar well-diffusion method. Overnight grown bacterial culture was transferred to sterile Petri plate with Mueller Hinton agar medium (Hi Media Laboratories Limited, Mumbai, India) and was spread with sterile spreader to create a lawn. Wells of $6 \mathrm{~mm}$ were punched into the previously seeded $\mathrm{MH}$ agar plates using sterile cork borer. About $80 \mu$ l of the different Ocimum extract was placed in the wells and allowed to diffuse for $2 \mathrm{hrs}$. at $4^{\circ} \mathrm{C}$ and the plates were incubated at $37^{\circ} \mathrm{C}$ for $24 \mathrm{hrs}$. The activity was determined by measuring the diameter of the inhibition zones for each well and expressed in millimeter.

\section{Determination of Minimal Inhibitory Concentration (MIC)}

The extracts that exhibited considerable activity were used for MIC determination. The extracts of the test samples were tested in four dose levels of $20 \mu \mathrm{l}, 40 \mu \mathrm{l}, 60 \mu \mathrm{l}$ and $80 \mu \mathrm{l}$. The overnight grown bacterial culture was transferred on $\mathrm{MH}$ agar plate and wells were punched out using a sterile $6 \mathrm{~mm}$ cork borer. Different concentration $(20-80 \mu l)$ of the extract was placed in separate wells, allowed to diffuse for $2 \mathrm{hrs}$. at $4^{\circ} \mathrm{C}$ and then the plates were incubated at $37^{\circ} \mathrm{C}$ for $24 \mathrm{hrs}$. The zone of inhibition was observed and the lowest concentration of the test sample showing zone of inhibition was recorded as the MIC.

\section{Results}

Phytochemical screening of the methanol extracts of Ocimum showed the presence of phenolic content, glycosides, anthraquinones, terpenoids, flavinoids, tannins, lignin and Saponins as chemical constituents.

Table 1- Qualitative Assay for Phytochemicals

\begin{tabular}{lccccc} 
Test & Osp & Osg & Og & Ob & Cb \\
FEHLING'S TEST & - & - & - & + & + \\
CARDIAC GLYCOSIDES & + & + & + & + & + \\
ANTHRAQUINONES & + & + & + & + & + \\
TERPENOIDS (SALKOWSKI) & + & + & + & + & + \\
PROTEINS & - & - & - & - & - \\
FLAVINOIDS & + & + & + & + & + \\
TANNINS & + & + & + & + & + \\
LIGNIN & + & + & + & + & + \\
SAPONINS & + & + & + & + & + \\
\hline
\end{tabular}

The results for phytochemical screening are shown in [Table-1] and the quantitative estimation of Phytochemicals is shown in [Table-2].

Table 2- Quantitative Assay for Phytochemicals

\begin{tabular}{lccccc|} 
Phytochemical & Osp & Osg & Og & Ob & Cb \\
\hline Tannins $\left(\mathrm{OD}_{670}\right)$ & 0.81 & 0.24 & 0.26 & 0.54 & 0.36 \\
Phenols $(\mathrm{mg} \mathrm{GAE} / \mathrm{g} \mathrm{dw})$ & 111.6 & 174 & 171.8 & 125.2 & 134.6 \\
Flavanoids (\%) & 6 & 4.66 & 3.83 & 5.5 & 2.83 \\
Alkaloids (\%) & 5.56 & 7.56 & 4.67 & 8.67 & 9.33 \\
\hline
\end{tabular}

The antioxidant activity of Ocimum species was determined by three different assays such as reducing power assay, 1-1-diphenyl2-picrylhydrazyl (DPPH) assay and Thiobarbituric acid (TBA) assay. Camphor basil showed maximum activity in reducing power assay at different concentrations as shown in [Fig-1].

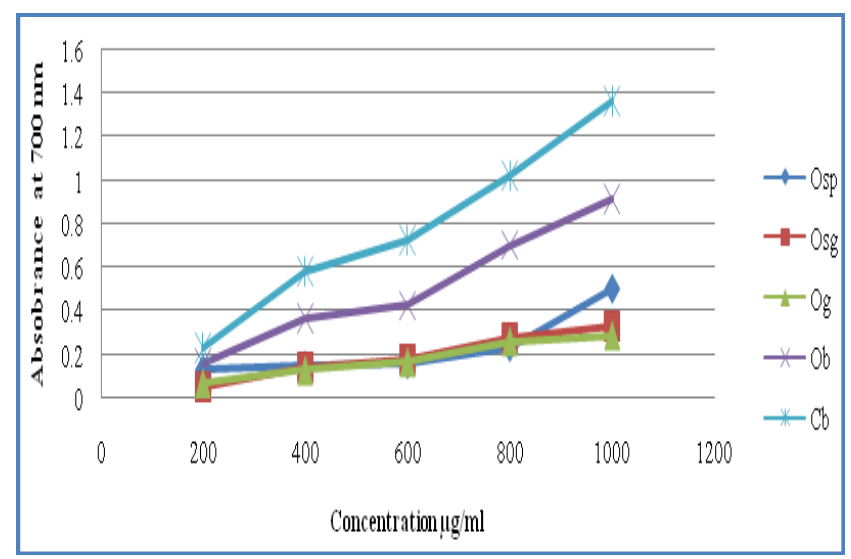

Fig. 1- Reducing Power Assay

In the DPPH method the absorbance was measured and the percent inhibition of the DPPH radical by Ocimum was calculated based on the measured absorbance. Antioxidant capacities in series of concentrations for Ocimum was used for calculating the percentage of antioxidant activity as showed in [Fig-2]. Camphor basil showed maximum antioxidant activity compared to other Ocimum species.

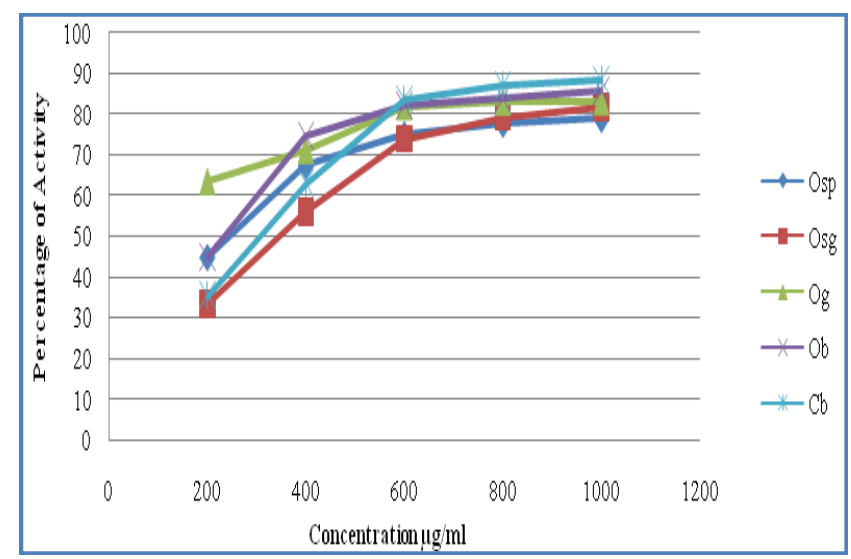

Fig. 2- Antioxidant activity by DPPH Assay

In the TBA assay Camphor basil was most active as an antioxidant followed by $O$. sanctum purple at various concentrations as shown in [Fig-3].

To determine the antibacterial activity, various solvent extracts like ethanol, Methanol, Propanol, chloroform, petroleum ether and Iso- 
amyl alcohol was evaluated and compared using agar diffusion method. All the test extracts of Ocimum showed significant antibacterial activity against tested pathogens. The antibacterial activity of O. sanctum purple, 0 . sanctum green, 0 . gratissimum, 0 . basilicum and Camphor basil are presented in [Fig-4-8] respectively. The isoamyl extract of Ocimum was found to be the most active and produced highest zone of inhibition. Isoamyl extract of 0 . sanctum purple produced $24 \mathrm{~mm}$ zone and 0 . sanctum green produced $32 \mathrm{~mm}$ zone against $B$. subtilis. Isoamyl extract of 0 . gratissimum produced $26 \mathrm{~mm}$ zone, 0 . basilicum produced $28 \mathrm{~mm}$ zone and Camphor basil produced $22 \mathrm{~mm}$ zone against $S$. typhi.

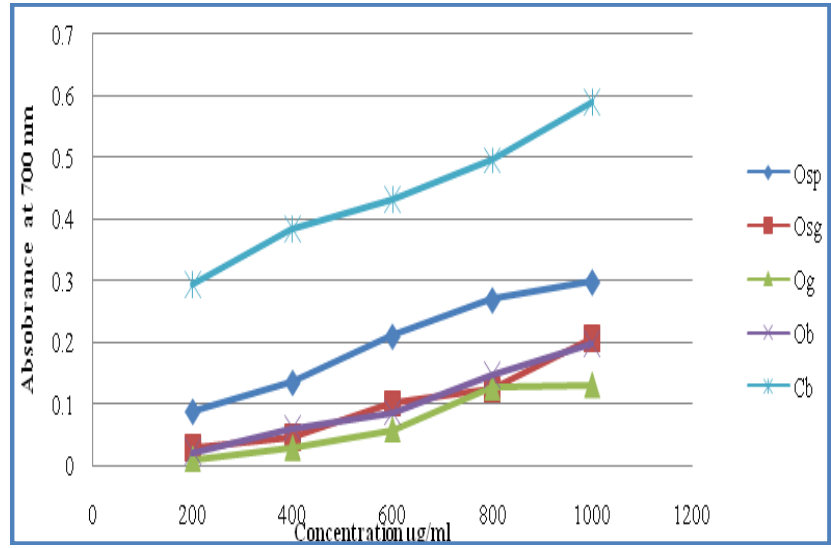

Fig. 3- Thiobarbituric Acid Assay

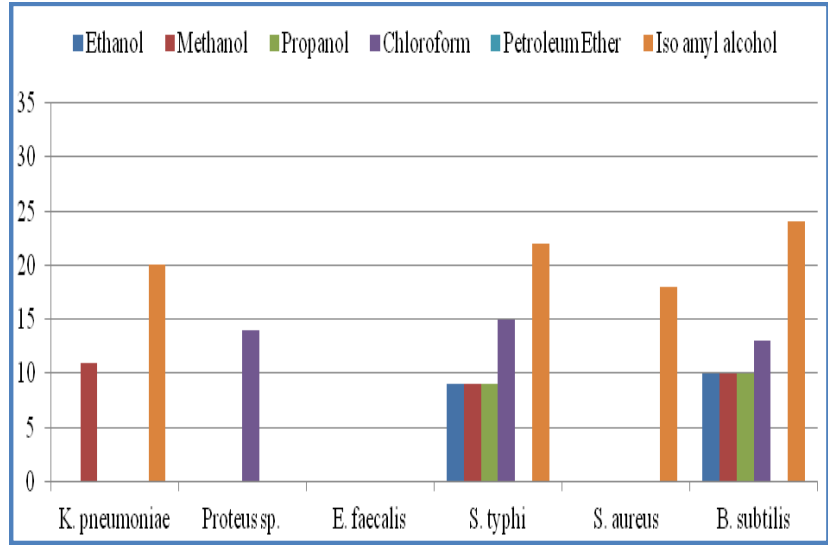

Fig. 4- Antibacterial Activity of Ocimum sanctum purple

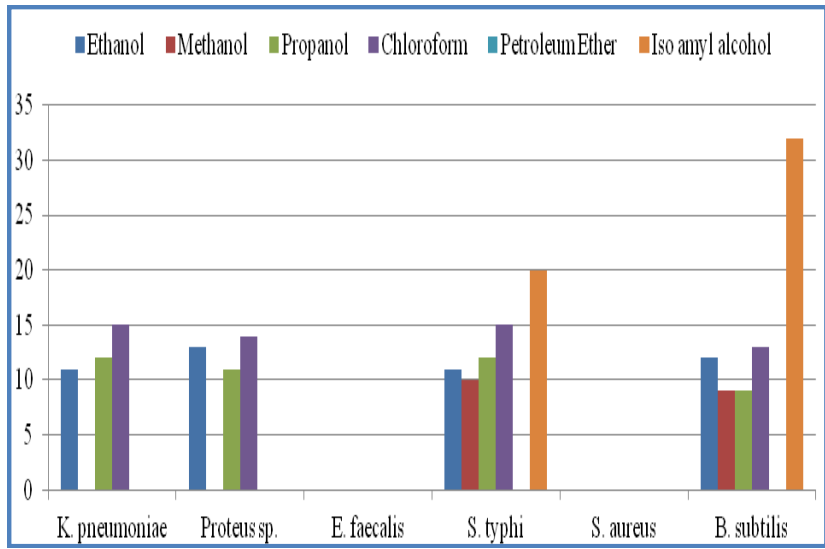

Fig. 5- Antibacterial Activity of Ocimum sanctum green

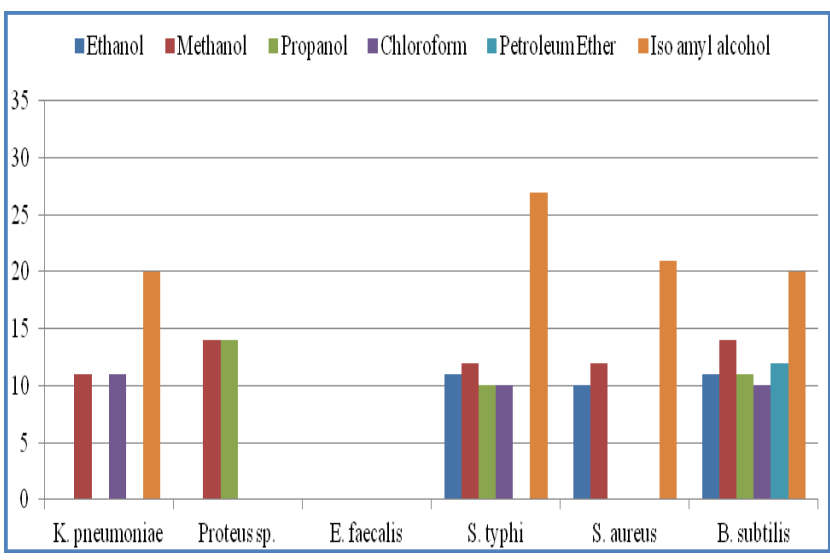

Fig. 6- Antibacterial Activity of Ocimum gratissimum

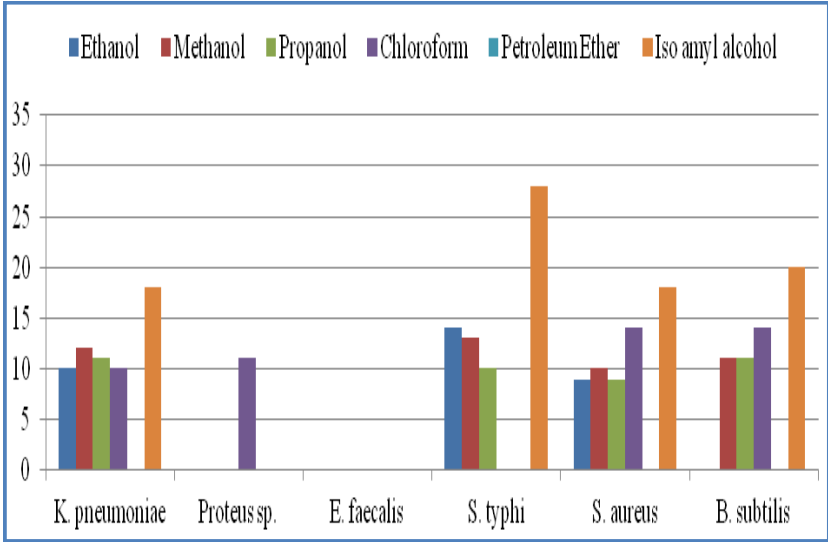

Fig. 7- Antibacterial Activity of Ocimum basilicum

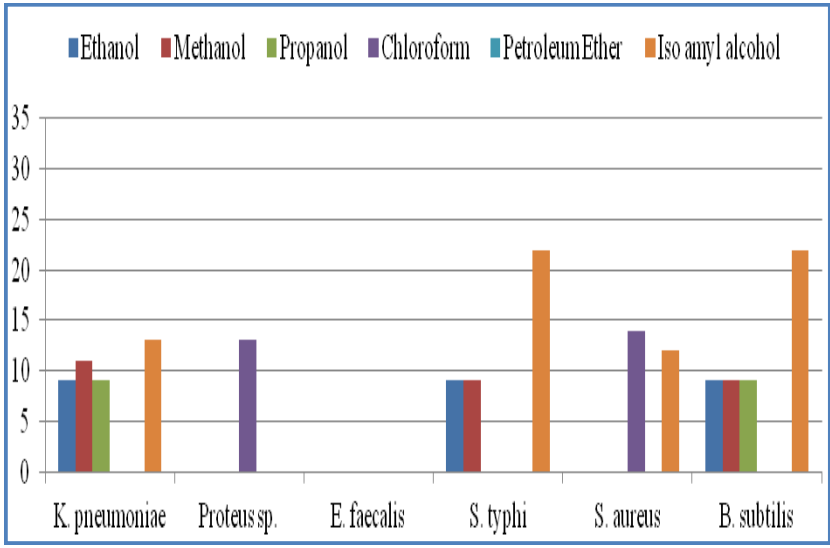

Fig. 8- Antibacterial Activity of Camphor basil (Ocimum kilimandscharicum)

In the MIC assay all the species exhibited diverse antimicrobial activity at varied concentrations as summarized in [Table-3].

The isoamyl alcohol extract was most active compared to other solvent extracts and $B$. subtilis and $S$. typhi were most sensitive among the tested microorganism.

\section{Discussion}

The Phytochemicals are either the product of plant metabolism or synthesized for defense purposes [4]. In the present investigation, the results of phytochemical analysis of Ocimum showed the pres- 
ence of chemical compound such as phenolic compounds, glycosides, flavanoids, tannins and saponins which account for their usefulness as medicinal plants. The DPPH radical scavenging activities of 0 . gratissimum was higher compared to other species at lower concentration: whereas, antioxidant activity of Camphor basil was higher in other assays. These differences might be due to the different principles of these assays: hence, we can construe that antioxidant activity cannot be compared by different antioxidant assays. Our antioxidant assay result corresponds to the earlier studies $[25,26]$.

Table 3- Minimal Inhibitory Concentration of Ocimum Species

\begin{tabular}{|c|c|c|c|c|c|c|}
\hline $\begin{array}{l}\text { Plant Sample and } \\
\text { Extraction solvent }\end{array}$ & \multicolumn{6}{|c|}{$\begin{array}{l}\text { K. pneumoniae S. typhii S. aureus E. faecalis Proteus sp. B. subtilis } \\
\text { Ocimum sanctum purple }\end{array}$} \\
\hline Ethanol Extract & & 80 & - & - & - & 60 \\
\hline Methanol Extract & 60 & 80 & - & - & - & 80 \\
\hline Propanol Extract & - & 80 & - & - & - & 60 \\
\hline Chloroform Extract & & 20 & - & - & 40 & 20 \\
\hline Petroleum Ether & & 0 & 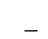 & _- & - & _- \\
\hline Isoamyl alcohol Extract & 20 & 20 & 20 & & & 20 \\
\hline \multicolumn{7}{|c|}{ Ocimum sanctum green } \\
\hline Ethanol Extract & 40 & 60 & - & - & 40 & 40 \\
\hline Methanol Extract & & 40 & - & - & & 60 \\
\hline Propanol Extract & 20 & 40 & - & - & 40 & 60 \\
\hline Chloroform Extract & 40 & 20 & - & - & 20 & 40 \\
\hline $\begin{array}{l}\text { Petroleum Ether } \\
\text { Isoamyl alcohol Extract }\end{array}$ & - & $\overline{20}$ & - & - & - & $\overline{20}$ \\
\hline \multicolumn{7}{|c|}{ Ocimum gratissimum } \\
\hline Ethanol Extract & & 40 & 60 & _- & _- & 60 \\
\hline Methanol Extract & 80 & 40 & 80 & - & 60 & 40 \\
\hline Propanol Extract & & 60 & - & - & 60 & 60 \\
\hline Chloroform Extract & 60 & 80 & - & - & _- & 60 \\
\hline Petroleum Ether & & & & - & - & 40 \\
\hline Isoamyl alcohol Extract & 20 & 20 & 20 & & _ & 20 \\
\hline \multicolumn{7}{|c|}{ Ocimum basilicum } \\
\hline Ethanol Extract & 60 & 20 & 80 & - & - & _- \\
\hline Methanol Extract & 60 & 40 & 80 & - & - & 60 \\
\hline Propanol Extract & 40 & 60 & 80 & 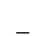 & 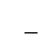 & 60 \\
\hline Chloroform Extract & 40 & - & 40 & - & 40 & 20 \\
\hline Petroleum Ether & & & & - & - & - \\
\hline Isoamyl alcohol Extract & 20 & 20 & 20 & & & 20 \\
\hline \multicolumn{7}{|c|}{ Camphor basil } \\
\hline Ethanol Extract & 80 & 80 & & & & 80 \\
\hline
\end{tabular}

The antimicrobial activities of different extracts of Ocimum were evaluated qualitatively and quantitatively against the pathogenic microorganisms by the presence or absence of inhibition zones and zone diameter. The isoamyl extract showed stronger and broader spectrum of antimicrobial activity compared to other solvent extracts. These results predict that isoamyl alcohol is a better solvent for consistent extraction of antimicrobial substances from Ocimum species. In the antimicrobial assay, among the tested pathogens $B$. subtilis and $S$. typhi were most sensitive for Ocimum extract and no inhibition activity was observed against $E$. faecalis. Our results are different from results of Adiguzel A., et al [27], in our study zone of inhibition was seen for Ethanol and Methanol extract of 0 . basilicum on Proteus sp. and $S$. aureus. The minimal inhibitory concentration was determined at different concentrations and varied for different species. Among the tested microorganism most were sensitive for isoamyl alcohol extract of all Ocimum species. As Ocimum is widespread in India, it can be recommended as an easily available and renewal source of antimicrobial agent in- stead of synthetic chemicals. The present findings indicate that Ocimum possesses compounds with antimicrobial properties against pathogenic microorganisms.

\section{References}

[1] Hammer K.A., Carson C.F., Riley T.V. (1999) Journal of Applied Microbiology, 86, 985-990.

[2] Adebolu T.T. and Salau Abiola Oladimeji (2005) Afr. J. Biotechnol., 4(7), 682-684.

[3] Afolabi C.A., Ibukun E.O., Emmanuel A., Obuotor E.M. and Farombi E.O. (2007) Sci. Res. Essay, 2(5), 163-166.

[4] Daniel V.N., Daniang I.E. and Nimyel N.D. (2011) IJET-IJENS, 11(6), 161-165.

[5] Ahmad I., Mehmood Z. and Mohammed F. (1998) J. Ethnopharmacol., 62, 183-193.

[6] Bushra Beegum N.R. and Ganga Devi T. (2003) Asian J. of Microbiol. Biotech. Env. Sc., 5(3), 319-322.

[7] Lee K.W., Everts H. and Beynen A.C. (2004) Int. J. Poult. Sci., 3, 738-752.

[8] Miura K., Kikuzaki H. and Nakatani N. (2002) J. Agric. Food Chem., 50, 1845-1851.

[9] Craig W.J. (1999) Am. J. Clin. Nutr., 70, 491-499.

[10]Bonjar G.H.S. and Farrokhi P.R. (2004) Niger. J. Nat. Prod. Med., 8, 34-39.

[11]Parekh J. and Chanda S. (2007) Afr. J. Biol. Res., 10, 175-181.

[12]Thaweboon S. and Thaweboon B. (2009) Southeast Asian J. Trop. Med. Public Health, 40(5), 1025-1033.

[13]Kath R.K. and Gupta R.K. (2006) Ind. J. Physiol. Pharmacol., 50, 391-396.

[14]Ramesh B. and Satkopan V.N. (2010) Ind. J. Clin. Biochem., 25(3), 307-310.

[15]Oliveira J.S., Porto L.A., Estevam C.S., Siqueira R.S., Alves P.B., Niculau E.S., Blank A.F., Almeida R.N., Marchioro M. and Quintans-Junior L.J. (2009) Bol. Latinoam. Caribe Plant. Med. Aromat., 8, 195-202.

[16]Javanmardi J., Stushnoff C., Locke E. and Vivanco J. M. (2003) Food Chemistry, 83(4), 547-550.

[17]Politeo O., Jukic M. and Milos M. (2007) Food Chemistry, 101, 379-385.

[18]Harbone J.B. (1998) Phytochemical Methods: A Guide to Modern Techniques of Plant Analysis, Chapman and Hall London.

[19]Obadoni B.O. and Ochuko P.O. (2001) Global J. Pure Appl. Sci., 8, 203-208.

[20]Van-Burden T.P. and Robinson W.C. (1981) J. Agric. Food Chem., 1, 77-82.

[21]Kahkonen M.P., Hopia A.I., Vuorela H.J., Rauha J., Pihlaja K., Kujala S.T. and Heinonen M. (1999) J. Agric. Food Chem., 47, 3954-3962.

[22]Boham A.B. and Kocipai A.C. (1994) Pacific Sci., 48, 458-463.

[23]Blois M.S. (1958) Nature, 181, 1199-1200. 
[24]Maryam Zahin, Farrukh Aqil and lqbal Ahmad (2009) International Journal of Pharmacy and Pharmaceutical Sciences, 1(1), 88-95.

[25]Hakkim F.L., Arivazhagan G. and Boopathy R. (2008) Journal of Medicinal Plants Research, 2, 250-257.

[26]Farrukh A., lqbal A. and Zafar M., (2006) Turk J. Biol., 30, 177183.

[27]Adiguzel A., Gulluce M., Sengul M., Ogutcu, Sahin F. and Karaman I. (2005) Turk. J. Biol., 29, 155-156. 